\title{
Legal Metrology and System for Calibration and Verification of the Radar Level Sensors
}

\author{
DOI: 10.12776/QIP.V20I1.694
}

\author{
Jaromír Markovič, Jozef Mihok, Stanislav Ďuriš, Zbyněk Schreier
}

Received 31 March 2016, Revised 26 May 2016, Accepted 17 June 2016

\begin{abstract}
Purpose: The paper deals with the legal metrology that is principally responsible for assuring the uniformity and correctness of measurements and presents the results of the scientific and research work in the cross-disciplinary fields. The design of the new measuring system for the verification of the radar level gauges.

Methodology/Approach: The requirements on performing verification of the measuring instruments are changed significantly, especially the requirement for reducing the time necessary for putting the measuring instruments out of service. Slovak legal metrology (SLM) has developed a number of its own systems for verification of the legally controlled measuring instruments.
\end{abstract}

Findings: The paper presents the results of the research activities aimed to refine and improve metrological continuity and metrological control of selected types of measuring instruments.

Research Limitation/implication: This paper are based on the theoretical and practical knowledge from the field of metrology, the analysis of the legislative and normative requirements on the measuring instruments metrological assurance, and knowledge gathered during the practical performance of the measuring instruments metrological control.

Originality/Value of paper: In the paper, there are presented those results of solving the tasks in the research and development fields that lead to the higher measurement accuracy, and to the elimination of the undesired influences that may occur during a measurement.

Category: Technical paper

Keywords: legal metrology; measurement accuracy; radar level gauges; measuring instrument; uncertainty 


\section{INTRODUCTION}

The legal metrology is the metrology applied in the practical life in order to assure the uniformity and correctness of measurements both on the national and international levels, creating thereby conditions for eliminating the technical barriers to trade and assuring the adequate protection of consumers. The legal metrology belongs to the technical regulations and requires for its operation a set of legislative and normative documents specifying the requirements on measurement procedures and measuring instruments. In the Slovak Republic, the basic terms for such a regulation are stipulated in the Act No. 142/2000 Coll. on metrology and in the implementing rule Decree No. 210/2000 Coll. on measuring instrument and metrological control. The Act on metrology specifies the legally controlled measuring instruments, that means the instruments used for measurements related with payments, health, security, property and environment protection that are liable to the mandatory metrological control before being put on the market, or in operation. Under the term the metrological control in operation (in use) the verification of the measuring instrument shall be understood that means the confirmation that its metrological characteristics are in compliance with the required metrological characteristics stipulated in the above mentioned Decree (Zgodavova and Slimak, 2008; Zgodavova, 2010). The radar level gauges also belong to the group of the legally controlled measuring instruments. They are used in the industry in relation with the storage of liquid and loos materials (Liberman, 2012). The verification and calibration of theses level gauges are the subject matter of the present article, in which the current status of the measuring systems for the level gauges control is described, including the description of the new designed equipment that contributes to reduce the impact of the measuring system arrangement on the measurement result.

\section{EQUIPMENT FOR THE CALIBRATION AND VERIFICATION OF THE RADAR LEVEL GAUGES}

In case of the automatic level gauges, two principles of the level height measurement are used: the contact and the non-contact ones. In case of the contact method, the liquid level height sensor is usually the float being in contact with the measured medium, while the float is immersed into the medium completely or partially. The non-contact (electronic) way of measurement uses the principle of the electromagnetic waves radiation and their reflection from the measured medium. Thanks to the progress in the field of electronics, the noncontact method becomes even more currently used - nowadays, we may observe the increase in number of non-contact level gauges, especially the radar ones (Oréans and Heide, 2000). The radar level gauges not only prove the good metrological properties, but they show a number of practical advantages as well, such as safety, absence of any movable mechanical parts, and their capability to function under the adverse environmental conditions (fog, high temperature, high pressure, aggressive ambient conditions). The initiative to develop a measuring 
system for the calibration and verification of the radar level gauges came from their manufacturers and suppliers themselves (Trebuňa, 2014; Pekarčíková, 2014; Popovič, 2015). The automatic level gauges are rather often used also for measurements related with payment purposes, as the legally controlled measuring instruments under the Act on metrology (Motzer, 2000).

\subsection{Physical principle}

The radar level sensors are based on two operating principles: the pulse radar sensor (TOF - Time of Flight) and the frequency modulated radar sensor (FMCW - Frequency Modulated Continuous Wave).

\section{Pulse radar sensor}

The basis for the distance determination is the measurement of the signal transition path time. The short clusters (so called packets) of the electromagnetic pulses of some milli or nanoseconds are sent by the transmitter, they bounce off the measured material, return back and are caught by the receiver. The number of waves and pulses times depend on the transmission frequency. The time delay of the transmitted packets is relatively long, enough for catching their refection by the receiver. The time difference $t_{\mathrm{d}}$ between the transmitted and received pulse is equal to the time that the signal needs to pass the distance from the transmitter to the measured material and back, i.e. double of the measured distance. The measured distance $L$ is continuously calculated using the formula:

$$
L=\frac{c \cdot t_{d}}{2}
$$

where $c$ is the speed of the electromagnetic waves propagation (see Fig. 1) (Burenin, Pakov and Sizikov, 1998; Gu et al., 2014).

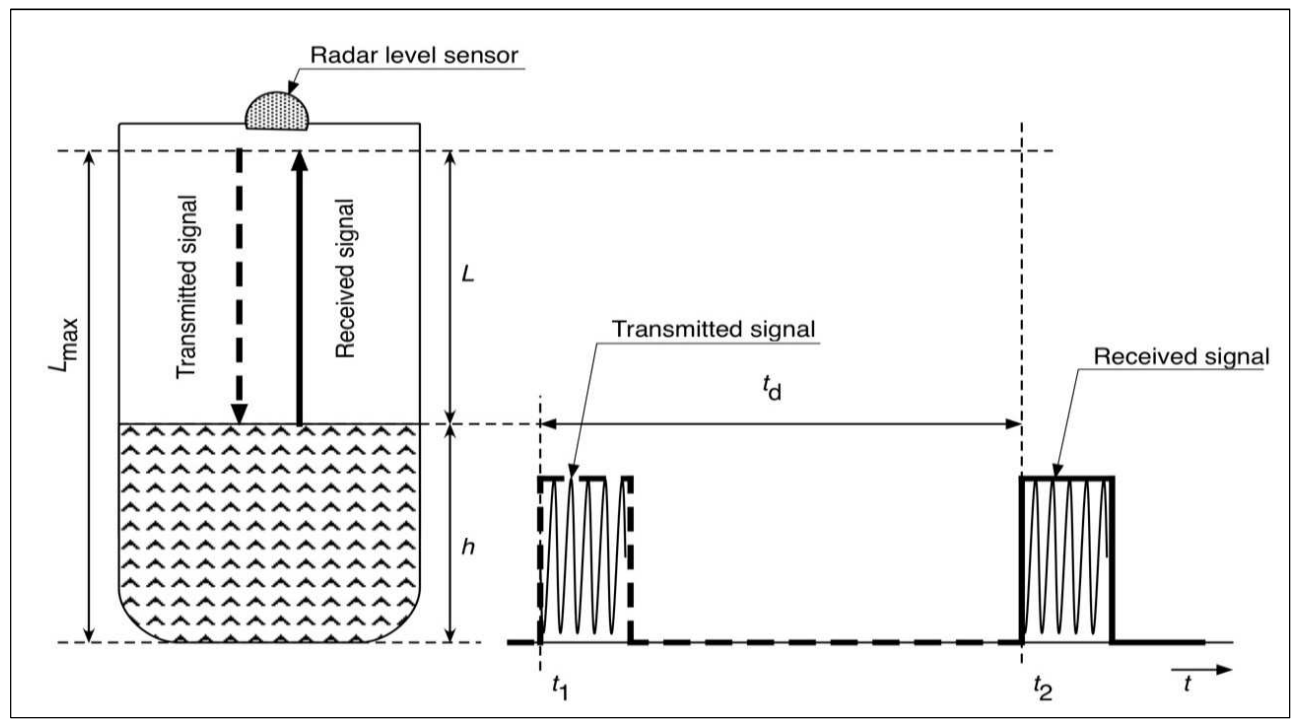

Figure 1-Operating principle of TOF radar level sensor 


\section{Frequency (FMCW) radar sensor}

The frequency modulated signal is transmitted continuously towards the measured object. The time slope of the transmitted frequency is linear and usually it has the saw-toothed shape. The reflected and received signal is compared with the transmitted signal, while the frequency difference $f_{\mathrm{d}}$ is measured corresponding to the time difference $t_{\mathrm{d}}$ for the calculation of the measured distance $L$. The frequency difference may be measured very precisely, and therefore also the measured distance may be determined with a high accuracy (see Fig. 2) (Kim and Lee, 2012; Wang et al., 2013; Mikuš and Hart'anský, 2013; Mikuš, Hart'anský and Čičáková, 2014).

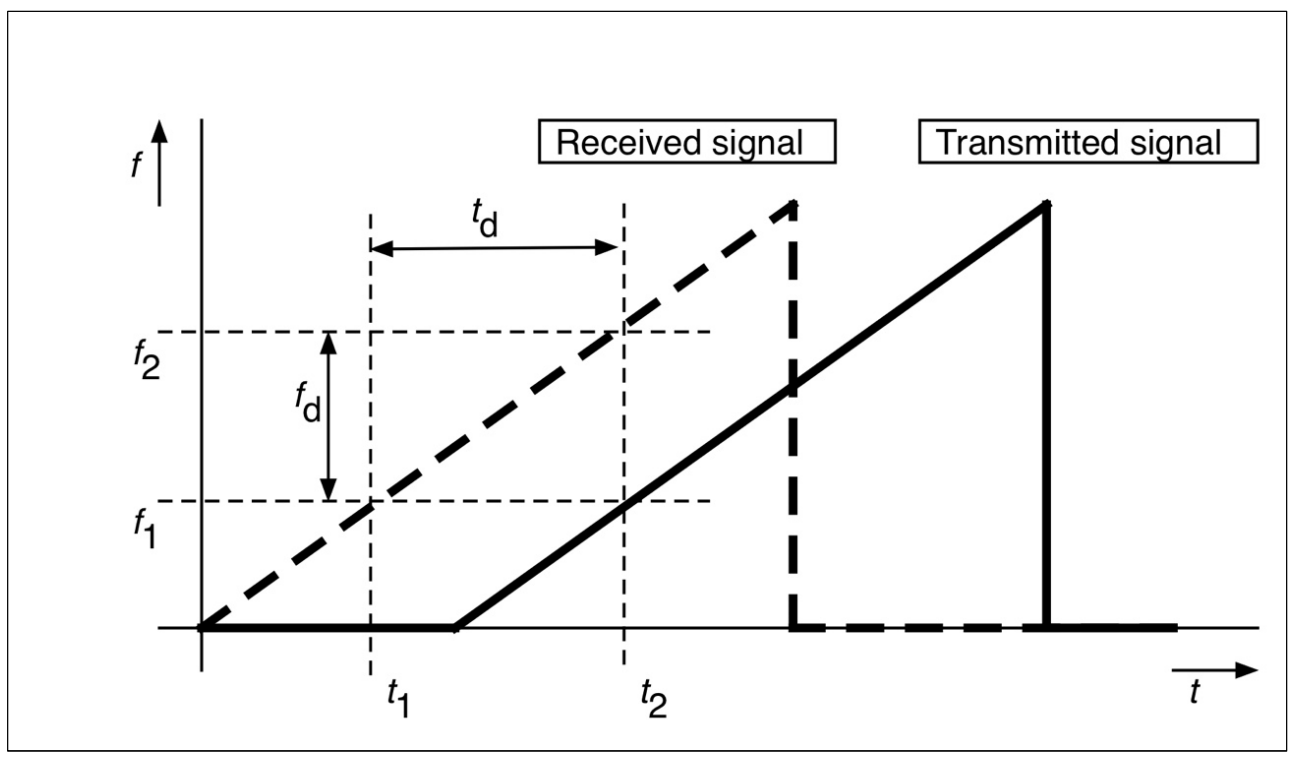

Figure 2 - Operating principle of FMCW radar level sensor

\subsection{Legislative and normative requirements}

When designing the above mentioned measuring system, the requirements of Decree No. 210/2000 Coll, Annex No. 68 "Automatic level gauges" on measuring instruments and metrological control were taken into consideration specifying both the requirements on maximum permissible error and methods of the level gauges verification. In addition, the design observes also the requirements of the International recommendation of OIML R 85 (Palenčár and Halaj, 1999; Palenčár, Kureková and Halaj, 2007).

\subsection{Principle of operation and description of realized measurement systems}

The operational principle of the original measuring system is based on the simulating the change of level using the reflection board - its distance from the calibrated/verified level gauge is measured by the laser interferometer 
(Michalecki, 2001; Wei, Xu and Ma, 2013). For the scheme of the realized measuring system for the level gauges calibration see Fig. 3. The reflection board (2) is mounted on the linear guide runner (1) of the total length of $16 \mathrm{~m}$. The angle of the reflection board may be set in two axes - vertical and horizontal - so it is set perpendicularly to the axis of the verified level gauge (4). The linear displacement of the reflection board is assured horizontally. The tested level gauge (4) is placed on the measurement table over which the standard - the laser interferometer is mounted (3) (Kim and Nguyen, 2003). The axes of the both devices shall be precisely aligned before the measurement, as any misalignment causes the cosine error of measurement. The precise appliances were prepared for fixing the measuring instruments (Mikuš, Hart'anský and Smieško, 2016).

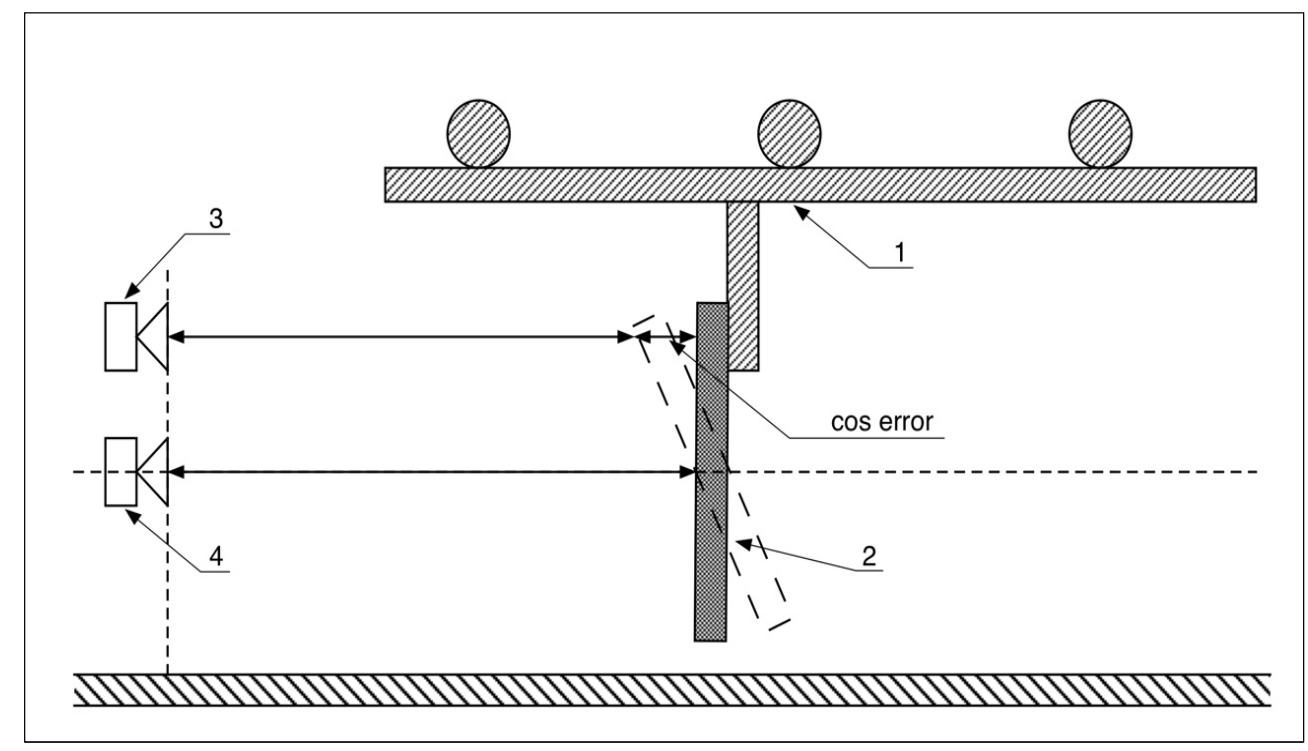

Figure 3 - Scheme of the original measurement system for calibration and verification of level gauges

In order to eliminate the cosine error, the new arrangement of the measuring system was designed. Therefore, in the new system, the interferometer is placed behind the reflection board; so its radiated beam is aligned with the radiated beam of the electromagnetic wave of the radar level gauge. This arrangement is shown in the Fig. 4. 


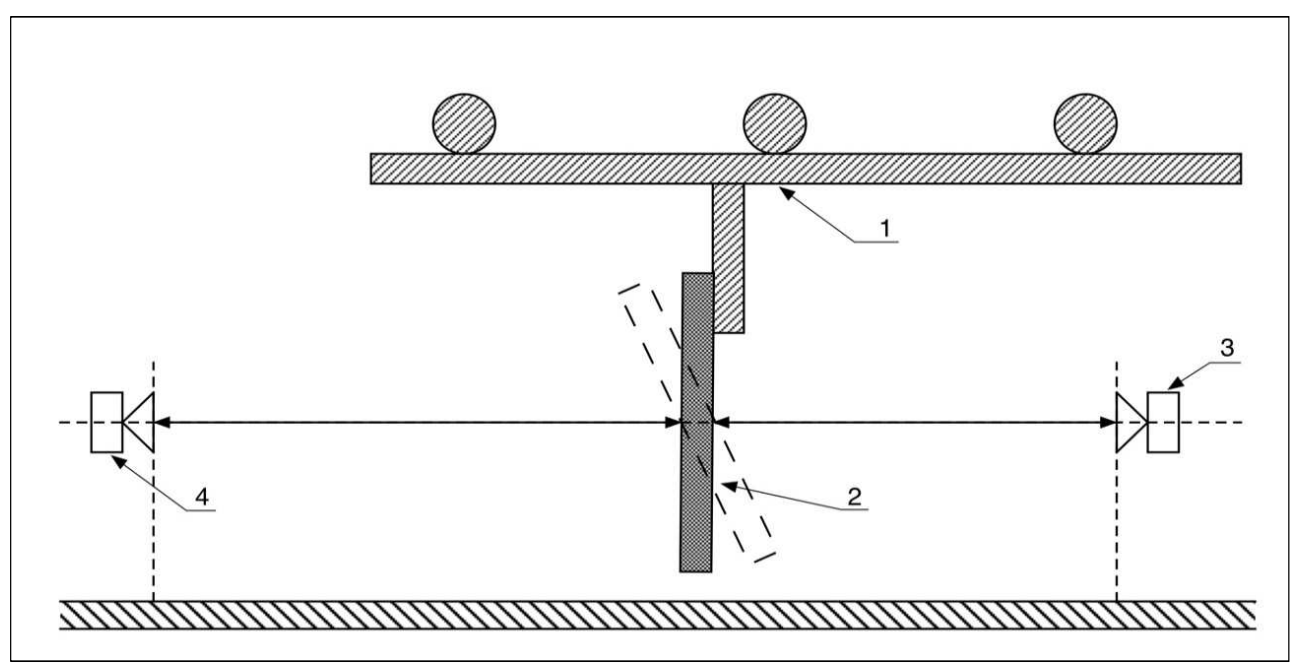

Figure 4 - Scheme of the new measurement system for calibration and verification of level gauges

\section{Reviewing the benefits of the new arrangement of measuring system}

In order to assess the new arrangement, the measurements before and after the adaptation of the measuring system were performed. The measurements were carried out within the length from $2 \mathrm{~m}$ up to $10.5 \mathrm{~m}$ in steps of $0.5 \mathrm{~m}$ so that the equal measurements conditions were assured. The measured results are recorded in the chart (see Fig. 5).

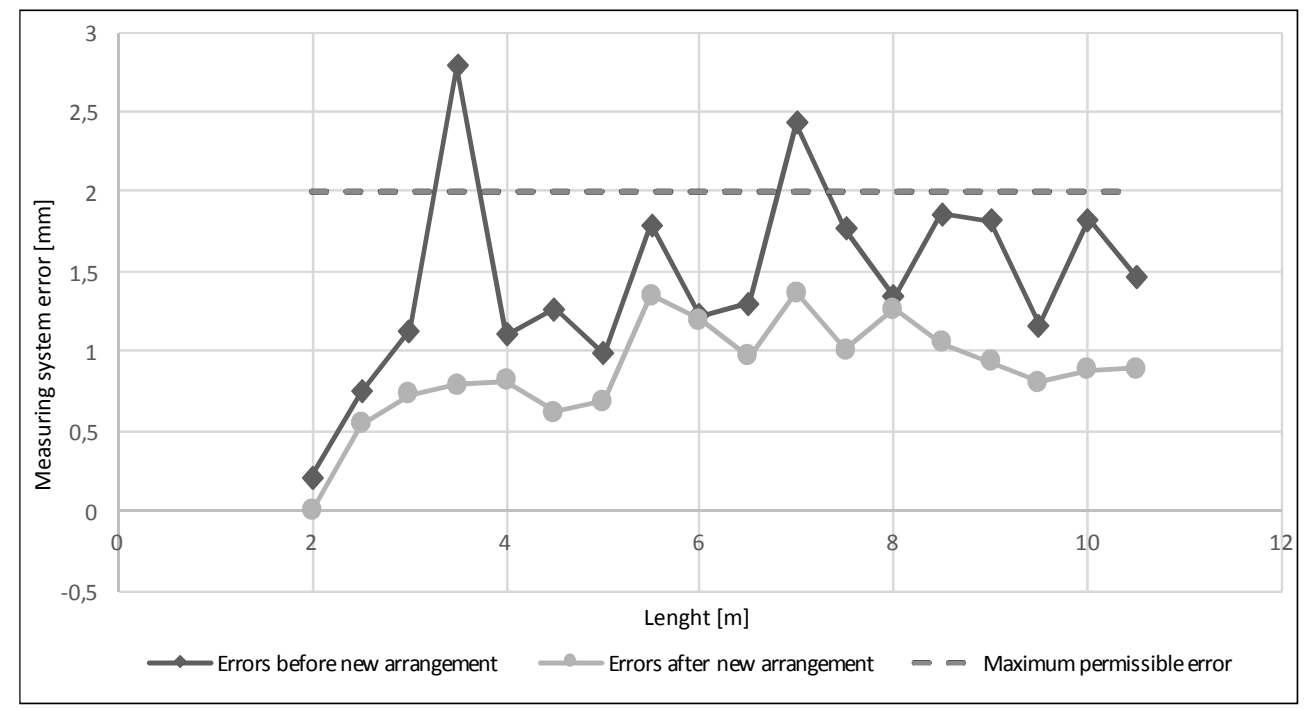

Figure 5 - Comparison of the measured values

The chart of the measured values shows clearly that the new arrangement of the measuring system resulted in the decreased influence of the cosine error on the measurement result. 


\section{CONCLUSION}

The radar method of the level measurements is getting under the spotlight still more and more; nevertheless the main obstacle for putting the respective legally controlled measuring instruments on the market up to now was the insufficient metrological assurance of the radar level gauges. The necessity to solve this situation resulted in the development of the new measuring equipment construction. However, this equipment had some gaps due to the cosine error. The new arrangement of the measuring system eliminated this default so that the error contribution caused by the original arrangement was decreased.

The use of the developed equipment will not be limited only to the radar level gauges, but it will enable to calibrate and verify also the level gauges operating on different measurement principles.

\section{ACKNOWLEDGMENTS}

This article was created by implementation of the grant project VEGA 1/0708/16 "Development of a new research methods for simulation, assessment, evaluation and quantification of advanced methods of production ".

\section{REFERENCES}

Burenin, P.V., Pakov, S.V. and Sizikov, O.K., 1998. Reducing the measurement error of pulse-radar level gauges for bulk media. Measurement Techniques, 41(6), pp. 533-535, ISSN 05431972.

Gu, C., Xu, W., Wang, G., Inoue, T., Rice, J.A., Ran, L. and Li, C., 2014. Noncontact Large-Scale Displacement Tracking: Doppler Radar for Water Level Gauging. IEEE Microwave and Wireless Components Letters, 24(12), pp.899901; DOI: 10.1109/LMWC.2014.2352852.

Kim, S.D. and Lee, J.H., 2012. A new transmitted-reference FMCW-UWB radar for gasoline tank level gauge. Proceedings of the 2012 International Conference on Image Processing, Computer Vision, and Pattern Recognition, IPCV 2012. 2, pp.1171-1174. ISBN: 978-160132225-8, Available at.

https://www.researchgate.net/publication/290573100_A_new_transmittedreference_FMCW-UWB_radar_for_gasoline_tank_level_gauge

Kim, S. and Nguyen, C., 2003. A displacement measurement technique using millimeter-wave interferometry (2003). IEEE Transactions on Microwave Theory and Techniques, 51(6), pp.1724-1728.

DOI: 10.1109/TMTT.2003.812575.

Liberman, V.V., 2012. Level measurement using radar level gauges. Automation and Remote Control, 73(3), pp.566-574, ISSN 00051179

DOI: $10.1134 / \mathrm{S} 0005117912030149$. 
Michalecki, G., 2001. Automatic calibration of gauge blocks measured by optical interferometry. Measurement Science Review, 1(1), pp.93-96. Available at: http://www.measurement.sk/Papers3/Michalec.pdf

Mikuš, P. and Hart'anský, R., 2013. The Errors in Radar Level Gauge Calibration. Measurement Scienece Review MEASUREMENT 2013, Proceedings of the 9th International Conference, Smolenice, Slovakia, pp.355-358. Available at: http://www.measurement.sk/M2013/doc/proceedings/355_Mikus-1.pdf

Mikuš, P., Hart’anský, R. and Čičáková, O., 2014. Diffraction Problem in Radar Level Gauge Verification. Universal Journal of Electrical and Electronic Engineering. 2(4), pp. 165-169, DOI: 10.13189/ujeee.2014.020404. Available at: http://www.hrpub.org/download/20140305/UJEEE4-14901774.pdf

Mikuš, P., Hart'anský, R. and Smieško, V., 2016. The proposal of the laboratories for calibration of radar level Gauges. Przeglad Elektrotechniczny, 92(2), pp.7274, ISSN 00332097, DOI: 10.15199/48.2016.02.21. Available at: http://pe.org.pl/articles/2016/2/21.pdf

Motzer, J., 2000. PULS RADAR gauge for level measurement and process control. Proceedings of the 1999 IEEE MTT-S International Microwave Symposium; Boston, MA, USA, 3, pp.1563-1566, ISSN 0149645X.

Oréans, L. and Heide, P., 2000. Novel Radar Level Gauge Using 24-GHzTechnology. Technisches Messen, 67(5), pp.214-219, ISSN 01718096.

Palenčár R. and Halaj, M., 1999. Metrologické zabezpečenie systémov riadenia kvality [Metrological assurance of the quality systems management]. 2nd ed. Bratislava: STU Bratislava. ISBN 80-227-1171-3.

Palenčár R., Kureková E. and Halaj, M., 2007. Meranie a metrológia pre manažérov [Measurement and metrology for managers]. Bratislava: STU Bratislava, ISBN 978-80-227-2743-3.

Pekarčíková, M., Trebuňa P. and Fil'o, M., 2014. Methodology for classification of material items by analysis abc/xyz and the creation of the material portfolio. Applied Mechanics and Materials, Vol. 611, pp.358-365, ISSN 1660-9336.

Popovič R., Kliment M., Trebuňa P. and Pekarčíková, M., 2015. Simulation as a tool for process optimization of logistic systems. Acta Logistica, 2(3), pp.1-5, Available at:

http://www.actalogistica.eu/issues/2015/III_2015_01_Popovic_Kliment_Trebuna _Pekarcikova.pdf [Accessed 5 September 2015].

Trebuňa P., Kliment M., Edl, M. and Petrik, M., 2014. Document creation of simulation model of expansion of production in manufacturing companies. Procedia Engineering, Vol. 96, pp.477-482,

Available at: http://www.sciencedirect.com/science/article/pii/S18777058140316 95 [Accessed 5 September 2015].

Wang, G., Gu, C., Rice, J., Inoue, T. and Li, C., 2013. Highly accurate noncontact water level monitoring using continuous-wave Doppler radar. WiSNet 
2013 - Proceedings: 2013 IEEE Topical Conference on Wireless Sensors and Sensor Networks - 2013 IEEE Radio and Wireless Week, RWW 2013. pp.19-21; DOI: 10.1109/WiSNet.2013.6488620.

Wei, M. , Xu, K.J. and Ma, Y., 2013. An echo signal processing method without reference curve for guided wave radar level gauge. IEEE International Conference on Control and Automation, ICCA. pp.972-977, DOI: 10.1109/ICCA.2013.6565025.

Zgodavova, K., 2010. Complexity of entities and its metrological implications, 0365-0367, Annals of DAAAM for 2010 \& Proceedings of the 21st International DAAAM Symposium, ISBN 978-3-901509-73-5, ISSN 1726-9679, pp.0365-0366, B. Katalinic (ed.), Published by DAAAM International, Vienna, Austria 2010; DOI:10.1073/pnas.1002194107, Available at:

http://www.daaam.info/Downloads/Pdfs/proceedings/proceedings_2010/20162_ Annals_1_head.pdf

Zgodavova, K. and Slimak, I., 2008. Advanced improvement of quality. Annals of DAAAM and Proceedings of the International DAAAM, Published by DAAAM International, Vienna, Austria 2010, pp.1551-1552, ISSN 17269679, ISBN 978390150968-1,

Available at: http://www.freepatentsonline.com/article/Annals-DAAAM-

Proceedings/225316745.html

\section{ABOUT THE AUTHORS}

Ing. Jaromír Markovič, PhD., Slovak legal Metrology, Banská Bystrica, Slovakia; e-mail: slm@slm.sk.

Dr. h. c. Prof. Ing. Jozef Mihok, PhD., Technical University of Košice, Faculty of Mechanical Engineering, Department of Industrial Engineering and Management, Košice, Slovakia; e-mail: jozef.mihok@tuke.sk.

Assoc. Prof. Ing. Stanislav Ďuriš, PhD., Slovak University of Technology in Bratislava; Faculty of Mechanical Engineering, Bratislava, Slovakia; e-mail: stanislav.duris@stuba.sk.

Ing. Zbyněk Schreier, CSc., Slovak Office of Standards, Metrology and Testing; Bratislava, Slovakia; e-mail: zbynek.schreier@normoff.gov.sk. 